\title{
Impact of a computerized system for evidence- based diabetes care on completeness of records: a before-after study
}

\author{
Pavel S Roshanov ${ }^{1}$, Hertzel C Gerstein ${ }^{2,3}$, Dereck L Hunt ${ }^{2,3}$, Rolf J Sebaldt ${ }^{2}$ and R Brian Haynes ${ }^{2,3,4^{*}}$
}

\begin{abstract}
Background: Physicians practicing in ambulatory care are adopting electronic health record (EHR) systems. Governments promote this adoption with financial incentives, some hinged on improvements in care. These systems can improve care but most demonstrations of successful systems come from a few highly computerized academic environments. Those findings may not be generalizable to typical ambulatory settings, where evidence of success is largely anecdotal, with little or no use of rigorous methods. The purpose of our pilot study was to evaluate the impact of a diabetes specific chronic disease management system (CDMS) on recording of information pertinent to guideline-concordant diabetes care and to plan for larger, more conclusive studies.
\end{abstract}

Methods: Using a before-after study design we analyzed the medical record of approximately 10 patients from each of 3 diabetes specialists (total $=31$ ) who were seen both before and after the implementation of a CDMS. We used a checklist of key clinical data to compare the completeness of information recorded in the CDMS record to both the clinical note sent to the primary care physician based on that same encounter and the clinical note sent to the primary care physician based on the visit that occurred prior to the implementation of the CDMS, accounting for provider effects with Generalized Estimating Equations.

Results: The CDMS record outperformed by a substantial margin dictated notes created for the same encounter. Only $10.1 \%(95 \% \mathrm{Cl}, 7.7 \%$ to $12.3 \%)$ of the clinically important data were missing from the CDMS chart compared to $25.8 \%(95 \% \mathrm{Cl}, 20.5 \%$ to $31.1 \%)$ from the clinical note prepared at the time $(p<0.001)$ and $26.3 \%(95 \% \mathrm{Cl}, 19.5 \%$ to $33.0 \%)$ from the clinical note prepared before the CDMS was implemented $(p<0.001)$. There was no significant difference between dictated notes created for the CDMS-assisted encounter and those created for usual care encounters (absolute mean difference, $0.8 \% ; 95 \% \mathrm{Cl},-8.5 \%$ to $6.8 \%$ ).

Conclusions: The CDMS chart captured information important for the management of diabetes more often than dictated notes created with or without its use but we were unable to detect a difference in completeness between notes dictated in CDMS-associated and usual-care encounters. Our sample of patients and providers was small, and completeness of records may not reflect quality of care.

\section{Background}

Successful diabetes care requires the active participation and informed self-management of engaged, educated, and motivated patients. The healthcare team, in turn, requires timely access at the point of care to comprehensive patient information, including but not limited to weight, blood pressure, current medications, glycosylated haemoglobin

\footnotetext{
* Correspondence: bhaynes@mcmaster.ca

²Department of Medicine, McMaster University, 1280 Main Street West, Hamilton, ON, Canada

${ }^{3}$ Hamilton Health Sciences, 1200 Main Street West, Hamilton, ON, Canada Full list of author information is available at the end of the article
}

(HbA1c), serum creatinine, LDL cholesterol, and urine albumin to creatinine ratio. Easy access to this information helps clinicians and patients to tailor and optimize care. Collection of standardized and well-defined data on each patient also allows for provider-level and clinic-level summary data for quality improvement.

An electronic, diabetes-specific, chronic disease management system (CDMS) that collects limited data during the clinical encounter and presents these data during future clinical encounters may help meet the needs of diabetic patients and their healthcare team.

\section{Biomed Central}


In a series of 6 systematic reviews covering 166 randomized controlled trials (RCTs), we recently synthesized the evidence of effectiveness of computerized clinical decision support systems for primary prevention [1], diagnostic test ordering [2], acute care [3], drug prescribing and management [4], therapeutic drug monitoring and dosing [5], and management of chronic diseases [6]. Several systems for management of diabetes have been tested in RCTs and a small majority improve practitioner performance, with less success for enhancing patient outcomes [7-25].

However, creating effective clinical information systems remains difficult. Because most systems are developed and tested in a few highly computerized environments with a long history of informatics excellence, the findings may not be generalizable to the more technologically naïve settings where most people receive care. Recent attention on health information technology as a means for better healthcare has made it increasingly important to design and test systems in a variety of settings.

\section{The P-PROMPT CDMS in the Diabetes Care and Research Centre}

With the help of diabetes specialists, Fig.P Software Inc. tailored its web-based chronic disease management system, the P-PROMPT CDMS, specifically for diabetes care and deployed it in the Hamilton Health Sciences Diabetes Care and Research Centre (DCRC), a hospitalbased, ambulatory care subspecialty clinic. The system's record structure is based on clinical practice in the DCRC and on the Canadian Diabetes Association practice guidelines for 2008, updated by us to 2010 to reflect more recent evidence. In a typical patient visit to the DCRC, physicians interview and examine patients in a room with an internet-connected computer. They always dictate a note summarizing the patient visit. Some practitioners tend to dictate their summary immediately after the patient leaves, while others defer this until the end of the day. Once transcribed, this dictated note is stored in the patient's paper records and communicated to their family doctor. Prior to the DCRC's recent adoption of the CDMS, this note, and any laboratory test results attached to it, comprised the longitudinal record of each patient.

Figures 1, 2, 3 show screenshots of the CDMS interface. During or after a patient visit, physicians enter directly into the CDMS information important for the management of diabetes, including each patient's demographic information, existing diagnoses, disease registry membership, and complete medication profile that includes current and past medications, along with reasons for discontinuation. The system is linked to the hospital's electronic laboratory records and summarizes the results of laboratory tests in a dashboard that displays longitudinal trends graphically; results from tests performed outside of the hospital must be entered manually. Finally, the CDMS can provide point-of-care, guideline-based, patient-specific decision support for practitioners and tailored self-management support messages intended for patients.

Before carrying out a large study to test the impact of the CDMS on diabetes care in the DCRC, we conducted a small pilot to help with sample size calculations. For this study we asked, "Does the CDMS impact the recording of clinical information pertinent to evidence-based diabetes care?"

\section{Methods}

Figure 4 summarizes the study design. This was a retrospective chart review of recent patient record entries (electronic charts and transcripts of dictated notes with any attached laboratory reports) generated as a result of CDMS-associated visits and previous transcripts of dictated notes (and attached laboratory reports) created without the help of the CDMS for the same patients. The Hamilton Health Sciences Research Ethics Board provided ethics approval for this study.

\section{Eligibility of patient records}

Patient records were eligible for review for patients who had their first complete CDMS-associated assessment at the clinic between January 1st 2011 and April 1st 2011 and previously without the help of the CDMS between June 1st 2009 and June 1st 2010, with no intervening DCRC physician visit (ignoring visits made to other health professionals).

\section{Primary outcome}

16 items of particular interest included the patient's weight; blood pressure; use of statins when appropriate; use of Angiotensin Converting Enzyme (ACE) inhibitors or Angiotensin II Receptor Blockers (ARBs) if appropriate; HbA1c; serum creatinine; LDL cholesterol; urine albumin to creatinine ratio (UACR); eye and foot examinations within the past year; any occurrence of severe hypoglycaemic episodes; number of non-severe hypoglycaemic episodes per month; cardiovascular events since the previous visit; and perfusion, light touch sensation, and skin integrity of the feet.

We counted the number of items in each record and calculated a missing fraction using Formula 1

$$
\text { Missing Fraction }=\left(\frac{16-\text { present }}{16}\right) \times 100
$$

For example, a record with 12 present items would have a missing fraction of $25 \%$. We found the mean missing fraction by first finding the missing fraction 


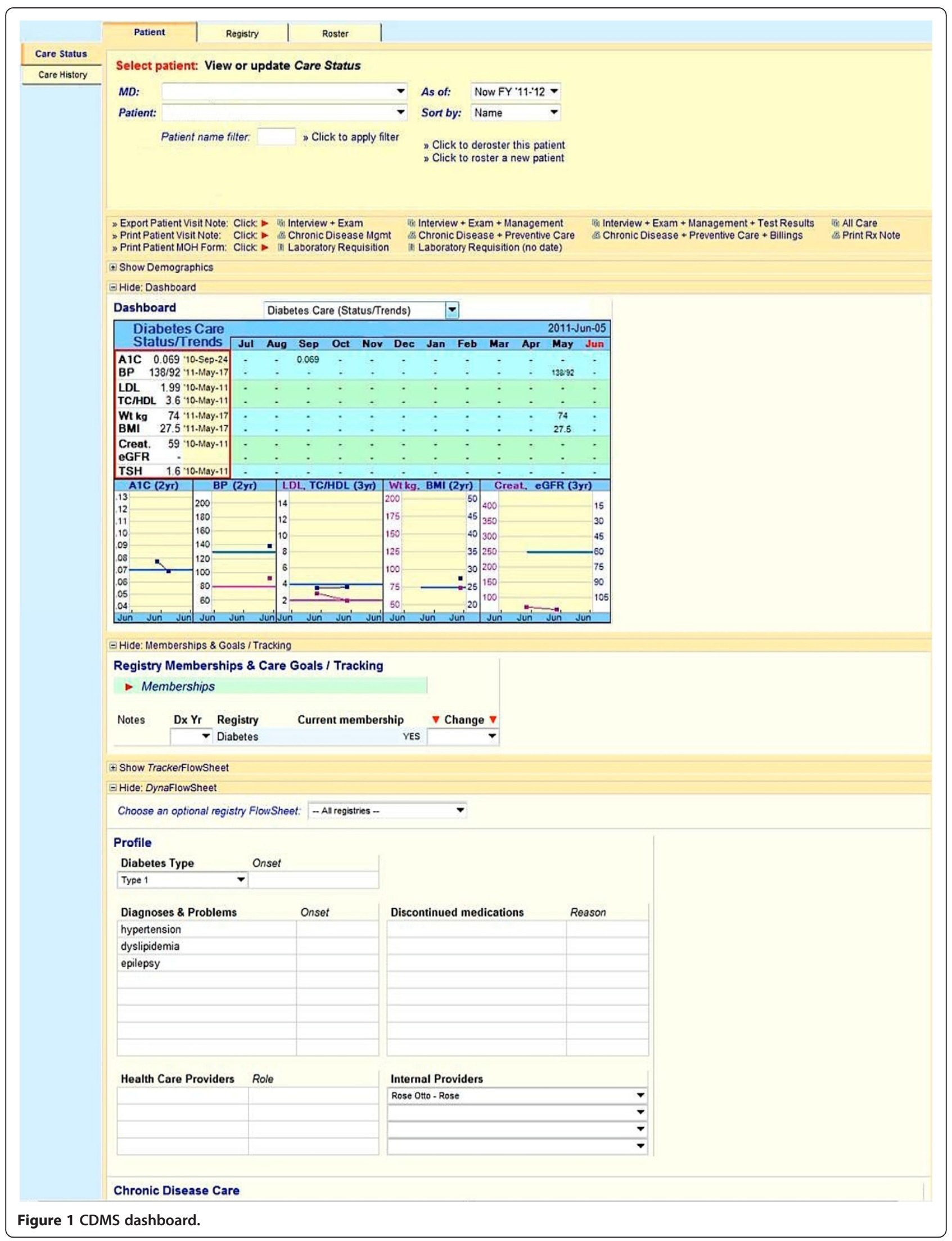




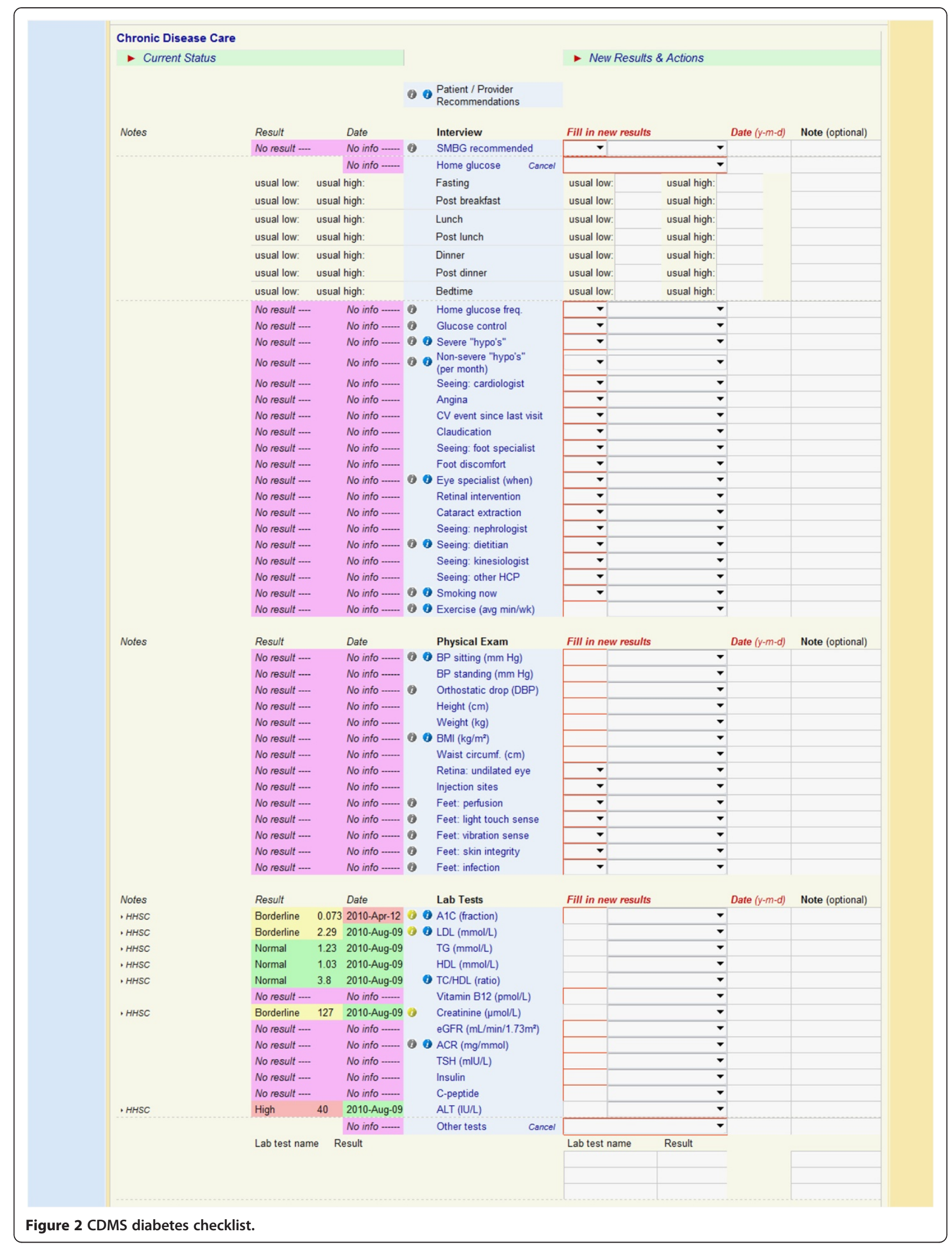




\begin{tabular}{|c|c|c|c|c|c|c|c|}
\hline & 2011-May-17 & 00 & $\begin{array}{l}\text { Other } \\
\text { Medications }\end{array}$ & Cancel & 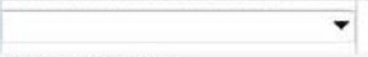 & & \\
\hline On visit entry: 2011-May-17 & & & On visit entry & Reset $y$ & Medication name & Dose & Copy All, \\
\hline rosuvastatin & $10-\mathrm{mg}$ od & & & $>$ & rosuvastatin & $10-m g$ od & copy > \\
\hline chlorthalidone & 25-mg od & & & > & chlorthalidone & $25-\mathrm{mg}$ od & copy $>$ \\
\hline Lamotrigine & $\begin{array}{l}100-\mathrm{mg}, 1.25 \\
\text { tabs bid } \\
600-\mathrm{mg} \text { at }\end{array}$ & & & $>$ & Lamotrigine & $100-\mathrm{mg}, 1.25$ tabs bii & ii copy > \\
\hline Carbamazepine cr & $\begin{array}{l}\text { breakfast, } 800-\mathrm{mg} \\
\text { at } 4: 00 \mathrm{pm} \text { and } \\
400-\mathrm{mg} \text { at bed }\end{array}$ & & & $>$ & Carbamazepine cr & $600-\mathrm{mg}$ at breakfast, & (copy $>$ \\
\hline trifluoperazine & 5-mg QID & & & $>$ & trifluoperazine & 5-mg QID & copy $>$ \\
\hline clomipramine & 25 -mg HS & & & $>$ & clomipramine & 25-mg HS & $c o p y>$ \\
\hline Ramipril & $10-\mathrm{mg}$ od & & & $>$ & Ramipril & $10-\mathrm{mg}$ od & copy > \\
\hline \multirow[t]{8}{*}{ Glucagon } & PRN & & & $>$ & Glucagon & PRN & copy $>$ \\
\hline & & & & $>$ & & & copy > \\
\hline & & & & > & & & $c o p y>$ \\
\hline & & & & $>$ & & & copy > \\
\hline & & & & $>$ & & & copy > \\
\hline & & & & $>$ & & & copy $>$ \\
\hline & & & & $>$ & & & copy > \\
\hline & & & & $>$ & & & copy > \\
\hline On visit exit: 2011-May-17 & & & On visit exit & Clear: & Medication name & Dose & Copy All \\
\hline rosuvastatin & 10 -mg od & & & $>$ & & & \\
\hline chlorthalidone & $25-\mathrm{mg}$ od & & & $>$ & & & \\
\hline Lamotrigine & $\begin{array}{l}100-\mathrm{mg}, 1.25 \\
\text { tabs bid } \\
600-\mathrm{mg} \text { at }\end{array}$ & & & > & & & \\
\hline Carbamazepine $\mathrm{cr}$ & $\begin{array}{l}\text { breakfast, } 800-\mathrm{mg} \\
\text { at } 4: 00 \mathrm{pm} \text { and } \\
400-\mathrm{mg} \text { at bed }\end{array}$ & & & $>$ & & & \\
\hline trifluoperazine & 5-mg QID & & & $>$ & & & \\
\hline clomipramine & 25-mg HS & & & $>$ & & & \\
\hline Ramipril & $10-\mathrm{mg}$ od & & & $>$ & & & \\
\hline Glucagon & PRN & & & $>$ & & & \\
\hline & & & & > & & & \\
\hline
\end{tabular}

for each patient's records and calculating their mean. We considered items to be present if clearly stated in the record or not relevant for a given patient. We used values for blood pressure and UACR to judge whether a patient's use of an ACE inhibitor or ARB should have been noted in that patient's record, as the relevance of these medications depends on those values. ACE inhibitors or ARBs are appropriate if the UACR is greater than 2.0, or if the patient is known to be hypertensive or blood pressure measured in clinic is above $130 / 80 \mathrm{mmHg}$. Statin medications are appropriate if LDL cholesterol levels exceed $2.0 \mathrm{mmol} / \mathrm{L}$, if a diabetic patient is male and over 45 years of age or female and over 50 years of age, or if the patient has ever experienced a stroke, myocardial infarction, or other major vascular event.

Our outcome of interest was the mean absolute difference in missing fraction between pairs of record types (see Analysis). Note that the CDMS does not directly assist dictation. CDMS-associated dictation refers to dictated notes that correspond to patient visits in which the CDMS was used.

\section{Measurement protocol}

From a larger group of 7 physicians in the DCRC, we selected for participation in this pilot study 3 attending physicians with a special interest in medical informatics. First, each clinician screened his patients' records sequentially for inclusion according to the eligibility criteria, beginning with the record updated most recently and moving to records updated progressively earlier until 10 eligible patient records were identified. Second, documentation pertaining to 2 separate clinical encounters was assessed within each record: the documentation generated during the recent CDMS-associated encounter and that which was generated during the next most recent encounter that did not include the CDMS, for a total of 61 encounters documented in 31 patient records. ${ }^{\text {a }}$

Records were assessed in two phases: 1) review of all dictated notes and 2) review of electronic charts from the CDMS (depending on whether the CDMS was used or not) created during the corresponding patient encounter. We ordered these review phases to minimize any impact of the CDMS chart assessment on assessment of the dictated note. 


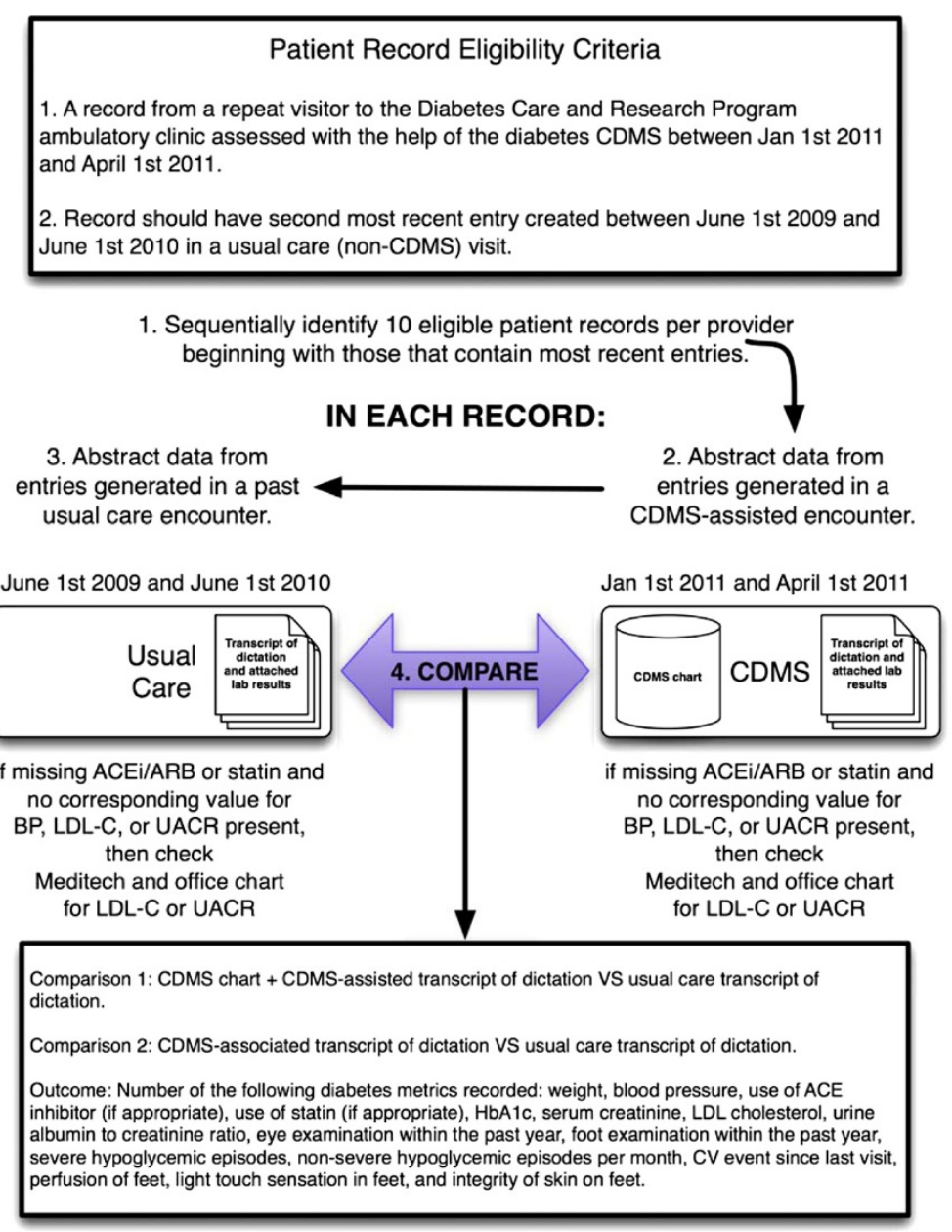

Figure 4 Study design. CDMS, Chronic disease management system; BP, Blood pressure; ACEi, Angiotensin Converting Enzyme inhibitor; ARB, Angiotensin II Receptor Blocker; HbA1C, Glycosylated haemoglobin; Cr, Creatinine; LDL, Low density lipoprotein cholesterol; UACR, Urinary albumin to creatinine ratio; CV, Cardiovascular.

\section{Analysis}

We estimated the mean differences and standard deviations between patient records for the proportion of missing items. We assessed 3 different record types for each patient (transcript of dictation from visit in which the CDMS was used [CDMS-associated transcript], transcript of dictation from usual care [non-CDMS] visit, and CDMS chart). For each patient, we calculated the absolute difference in the missing fraction in each of the following pairs:

1. CDMS-associated transcript of dictation VS usual care transcript of dictation

2. CDMS chart VS CDMS-associated transcript of dictation

3. CDMS chart VS usual care transcript of dictation

All patients received care from 1 of 3 providers. We used Generalized Estimating Equations (GEE) [26] to perform our comparisons. GEE allowed us to construct multi-level linear models with a structure that takes into account similarity between records created by the same provider. We measured this similarity using the Intraclass Correlation Coefficient (ICC) [26]. The ICC ranges from 0 to 1 ; values close to 0 mean that there is little relationship between the records of the same provider while values closer to 1 suggest a strong relationship. An ICC of 1 indicates that completeness for a given type of record is constant for records created by the same provider, making the effective sample size of the study 3 instead of 31. We performed all analyses using the STATA Statistical Software package, version 11.2 [27].

\section{Results}

Table 1 describes the data; Table 2 presents results of the statistical comparisons and, along with Figure 5, summarizes missing fractions corresponding to each record type overall and by provider. 
Table 1 Descriptive statistics

\begin{tabular}{lccc}
\hline Group & N & \multicolumn{2}{l}{ “Missing" fraction } \\
\cline { 2 - 4 } & & Mean (SEM)\% & $\mathbf{9 5 \% ~ C l}$ \\
\hline Usual-care note & $\mathbf{3 0}$ & $\mathbf{2 6 . 2 5}(\mathbf{3 . 3 2})$ & $\mathbf{1 9 . 4 7 , 3 3 . 0 3}$ \\
\hline Provider 1 & 10 & $23.75(5.00)$ & $12.44,35.06$ \\
\hline Provider 2 & 9 & $43.75(5.89)$ & $30.16,57.34$ \\
\hline Provider 3 & 11 & $14.20(1.90)$ & $9.97,18.44$ \\
\hline CDMS-associated note & $\mathbf{3 1}$ & $\mathbf{2 5 . 8 1 ( 2 . 6 0 )}$ & $\mathbf{2 0 . 4 8 , 3 1 . 1 2}$ \\
\hline Provider 1 & 10 & $21.25(2.98)$ & $14.52,27.98$ \\
\hline Provider 2 & 10 & $38.13(4.00)$ & $29.07,47.18$ \\
\hline Provider 3 & 11 & $18.75(4.04)$ & $9.74,27.76$ \\
\hline CDMS chart & $\mathbf{3 1}$ & $\mathbf{1 0 . 0 8 ( 1 . 1 8 )}$ & $\mathbf{7 . 6 6 , 1 2 . 5 0}$ \\
\hline Provider 1 & 10 & $10.00(1.02)$ & $7.69,12.31$ \\
\hline Provider 2 & 10 & $15.00(1.38)$ & $11.87,18.13$ \\
\hline Provider 3 & 11 & $5.68(2.30)$ & $0.55,10.81$
\end{tabular}

CDMS, Chronic disease management system; SEM, Standard error of the mean; $\mathrm{Cl}$, Confidence interval.

The CDMS chart outperformed the CDMS-associated dictated note by a substantial margin (mean missing fraction, $10.1 \%, 95 \%$ CI $[7.7 \%$ to $12.3 \%$ ] vs. $25.8 \%, 95 \%$ CI [20.5\% to $31.1 \%]$, respectively; absolute difference, $15.8 \%, 95 \%$ CI $[11.4 \%$ to $20.1 \%])$. It similarly outperformed the usual-care dictated note (mean missing fraction, $26.3 \%, 95 \%$ CI $[19.5 \%$ to $33.0 \%]$; absolute mean difference, $16.5 \%, 95 \%$ CI [10.6\% to $22.4 \%])$. However, there was no difference between the usual-care dictated note and the CDMS-associated dictated note (absolute mean difference, $0.8 \%$; $95 \% \mathrm{CI},-8.5 \%$ to $6.8 \%$ ).

Figure 6 presents the number of times each of the 16 items was considered missing across the 3 record types.

Table 2 Comparison results

\begin{tabular}{|c|c|c|c|}
\hline \multirow[t]{2}{*}{ Group } & \multirow[t]{2}{*}{$\mathbf{N}$} & \multicolumn{2}{|c|}{ Absolute difference in"Missing" fraction } \\
\hline & & Mean $\Delta\left(\mathrm{SEM}^{*}\right) \%$ & $95 \% \mathrm{Cl}^{*}$ \\
\hline $\begin{array}{l}\text { CDMS-associated } \\
\text { note - CDMS chart }\end{array}$ & 31 & $15.75(2.22)$ & $11.39,20.11 * *$ \\
\hline Provider 1 & 10 & $11.25(3.20)$ & $4.01,18.49^{* *}$ \\
\hline Provider 2 & 10 & $23.13(3.85)$ & $14.42,31.83^{* *}$ \\
\hline Provider 3 & 11 & $13.07(4.08)$ & $3.97,22.16^{* *}$ \\
\hline $\begin{array}{l}\text { Usual-care - } \\
\text { CDMS chart }\end{array}$ & 30 & $16.47(3.02)$ & $10.55,22.41 * *$ \\
\hline Provider 1 & 10 & $13.75(5.65)$ & $0.96,26.54^{* *}$ \\
\hline Provider 2 & 9 & $29.17(6.25)$ & $14.75,43.58^{* *}$ \\
\hline Provider 3 & 11 & $8.52(3.29)$ & $1.18,15.86^{* *}$ \\
\hline $\begin{array}{l}\text { Usual-care note - } \\
\text { CDMS-associated }\end{array}$ & 30 & $0.82 \%(3.91)$ & $-8.48,6.84$ \\
\hline Provider 1 & 10 & $2.50(4.95)$ & $-8.69,13.69$ \\
\hline Provider 2 & 9 & $5.56(6.46)$ & $-9.34,20.45$ \\
\hline Provider 3 & 11 & $-4.55(4.62)$ & $-14.85,5.76$ \\
\hline
\end{tabular}

*Estimated assuming an exchangeable covariance structure [26]; ${ }^{* *} p \leq 0.05$; CDMS, Chronic disease management system; SEM, Standard error of the mean; $\mathrm{Cl}$, Confidence interval.
We did not conduct statistical tests to determine the greatest contributors to the missing fraction, but serum creatinine, UACR, hypoglycemia, and perfusion of feet appear to contribute most often.

The ICC for the difference in missing fraction between CDMS charts and CDMS-associated dictation transcripts created by the same practitioner was 0.15 ( $95 \mathrm{CI}$, 0.00 to 0.55 ), 0.25 (0.00 to 0.75 ) for the difference in missing fraction between CDMS charts and usual care transcripts, and 0 (0.00 to 0.20$)$ for the difference in missing fraction between CDMS-associated transcript and usual care transcript. These estimates are very imprecise because only three providers were included in the study.

\section{Discussion}

We discovered that CDMS charts capture information important for the management of diabetes more often than dictated notes created with or without its use. There was no difference between the two types of dictated notes, suggesting that use of the CDMS neither improved nor hindered the quality of the dictated note among diabetes specialists. We chose the target sample size of 30 patients to help us calculate sample size for future studies of this system, and did not explicitly power the study to detect differences in completeness. With so few patients, we cannot dismiss the possibility of positive or negative impact. Indeed, confidence intervals ranged from substantial improvement to substantial decline in completeness of dictated notes with use of the CDMS.

Completeness of records is only a distant surrogate marker of clinical care quality. It is possible that the items in our assessment form were biased toward the CDMS chart. The CDMS may elicit responses to items that the practitioner deems irrelevant for the dictated summary of a particular clinical encounter. For example, an unremarkable foot exam may not be mentioned in the dictation but the practitioner may still indicate in the CDMS chart (which provides a relevant drop-down menu) that it was performed. In this situation, the patient does not gain additional benefit despite having a more complete CDMS chart.

While the dictated notes did not change with CDMS use, storing more complete records in a structured electronic format allows for other quality improvement interventions. For example, the CDMS includes pointof-care, guideline-based, patient-specific decision support for practitioners and tailored self-management support messages intended for patients. A number of systems that engage diabetic patients and their practitioners have demonstrated benefit in randomized trials $[8-10,12]$. The CDMS is also being enhanced to provide periodic clinician-level performance feedback, which was previously found to improve the quality of care when combined with patient-specific decision support [28]. 


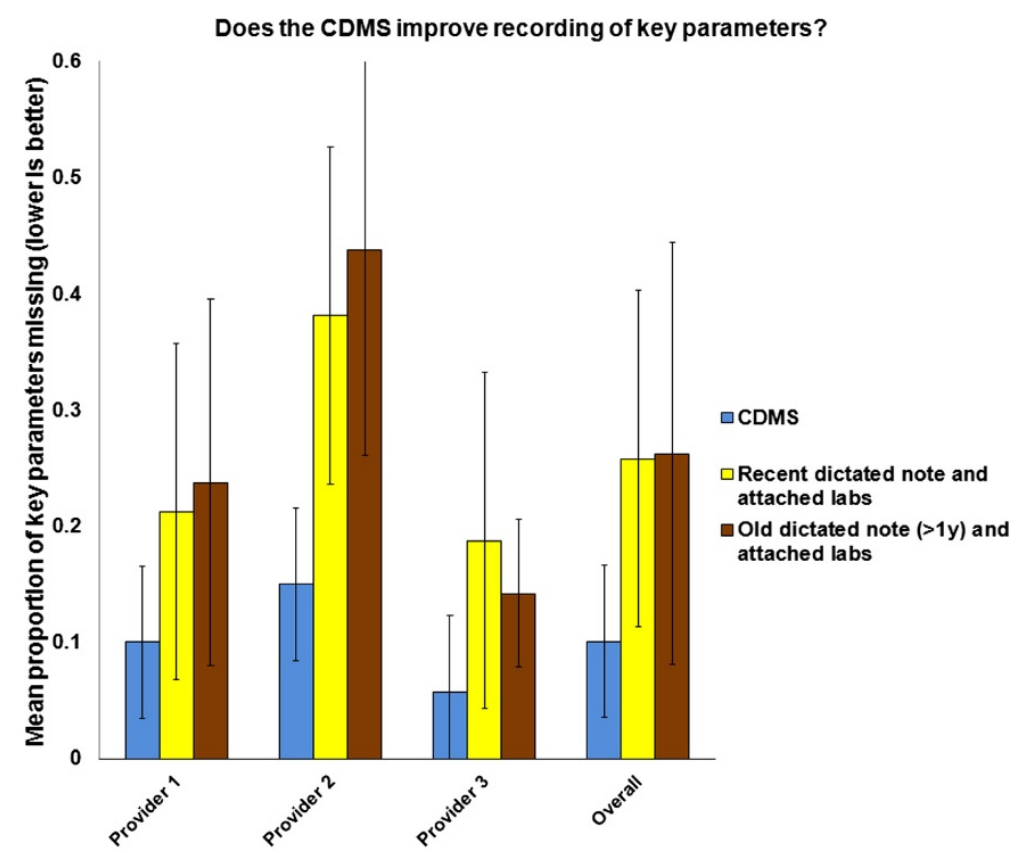

Figure 5 Does the CDMS improve recording of key parameters? Key parameters were missing less often from the CDMS chart than from dictated notes. Error bars indicate 95\% confidence intervals.

Providers were happy with the ability to track patients' progress longitudinally, and with access to past test results and medication profiles. We can expect some benefit to patient health if particular management decisions require that the practitioner refer to a detailed historical care record. Studies much larger and lengthier than are typically feasible with local computerized interventions would be necessary to detect these benefits, which may be rare but still meaningful given the high prevalence of diabetes.

A specialized diabetes clinic appears to lend itself well to the use of an electronic record and disease

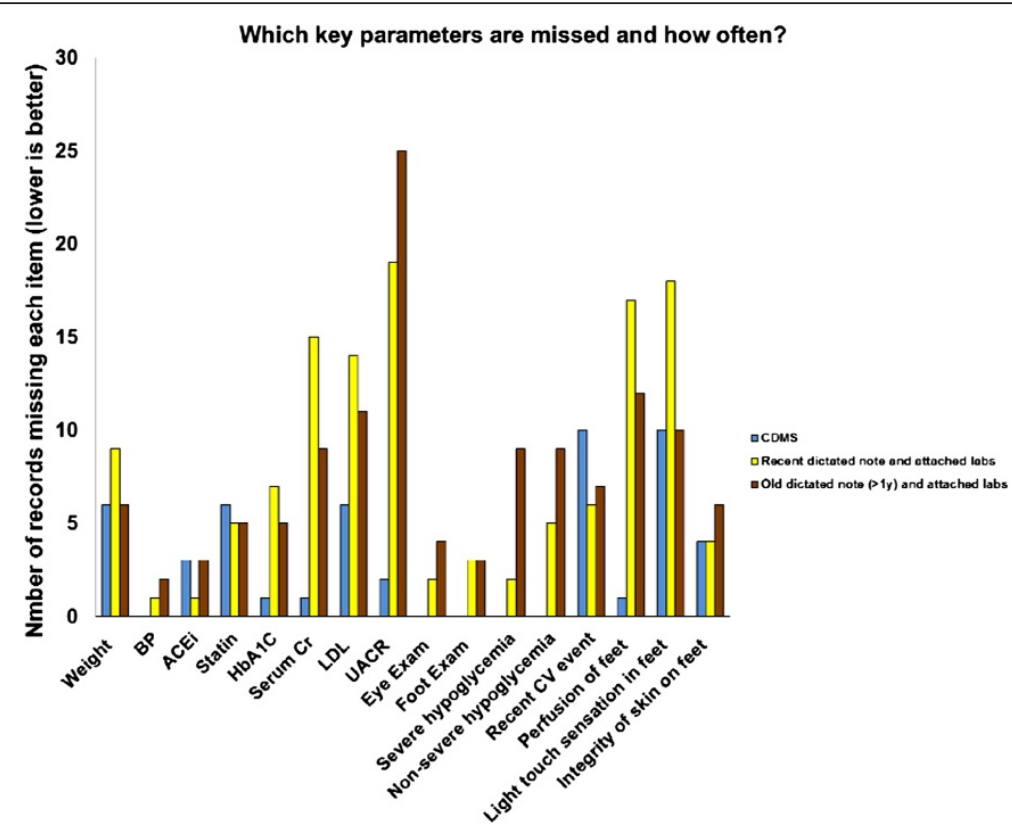

Figure 6 Which key parameters are missed and how often? CDMS, Chronic disease management system; BP, Blood pressure; ACEi, Angiotensin Converting Enzyme inhibitor; ARB, Angiotensin II Receptor Blocker; HbA1C, Glycosylated haemoglobin; Cr, Creatinine; LDL, Low density lipoprotein cholesterol; UACR, Urinary albumin to creatinine ratio; CV, Cardiovascular. 
management system tailored to the needs of diabetes specialists and their patients. Our findings, however, may not be generalizable to primary care, where most diabetic patients are managed. Primary care physicians address a wide range of ailments within a single patient due to multimorbidity [29] and across patients owing to a broad scope of practice. It may, therefore, be difficult for general practitioners to adopt a detailed system for the management of just one disease.

\section{Conclusions}

In this small, retrospective, before-after pilot study, the CDMS chart captured information important for the management of diabetes more often than dictated notes created with or without its use, but we were unable to detect a difference in completeness between notes dictated in CDMS-associated and usual-care encounters. Larger studies will assess the impact of this system on completeness of records and other, better indexes of care quality.

\section{Endnote}

${ }^{a}$ One usual care dictated note was not available.

\section{Competing interests}

One usual care dictated note was not available.RJS is the owner of Fig.P Software Incorporated, which develops the chronic disease management system discussed in this study. Other authors declare no competing interests.

\section{Acknowledgements \\ This study was supported by a grant from the Innovation Fund of the Hamilton Academic Health Sciences Organization Alternate Funding Plan under the auspices of the Ontario Ministry of Health and Long Term Care and the Ontario Medical Association. PSR was supported financially by a Canadian Institutes of Health Research 'Banting and Best' Master's Scholarship, a McMaster University research scholarship, and a 'Jack Banham Hargreaves' MD/PhD Scholarship from the University of Western Ontario.}

\section{Author details \\ ${ }^{1}$ Schulich School of Medicine and Dentistry, The University of Western Ontario, 1151 Richmond Street, London, ON, Canada. ${ }^{2}$ Department of Medicine, McMaster University, 1280 Main Street West, Hamilton, ON, Canada. ${ }^{3}$ Hamilton Health Sciences, 1200 Main Street West, Hamilton, ON, Canada. ${ }^{4}$ Health Information Research Unit, Department of Clinical Epidemiology and Biostatistics, McMaster University, 125 Communications Research Laboratory, 1280 Main Street West, Hamilton, ON L8S4K1, Canada.}

\section{Authors' contributions}

PSR designed the study, acquired, analyzed, and interpreted data; drafted and critically revised the manuscript. HCG conceived the study, contributed to the design of the diabetes-specific CDMS and to the design of the study, acquired and interpreted data and critically revised the manuscript. RJS created the diabetes-specific CDMS and critically revised the manuscript. DLH contributed to the design of the diabetes-specific CDMS and this study; acquired data, and critically revised the manuscript. $\mathrm{RBH}$ contributed to the design of the diabetesspecific CDMS and this study, provided study supervision, acquired data and critically revised the manuscript. All authors read and approved the final manuscript.

Received: 15 January 2012 Accepted: 7 July 2012

Published: 7 July 2012

\section{References}

1. Souza NM, Sebaldt RJ, Mackay JA, Prorok J, Weise-Kelly L, Navarro T, Wilczynski N, Haynes RB, the CCDSS Systematic Review Team: Computerized clinical decision support systems for primary preventive care: a decision-maker-researcher partnership systematic review of effects on process of care and patient outcomes. Implement Sci 2011, 6:87.

2. Roshanov PS, You JJ, Dhaliwal J, Koff D, Mackay JA, Weise-Kelly L, Navarro T, Wilczynski NL, Haynes RB, the CCDSS Systematic Review Team: Can computerized clinical decision support systems improve practitioners' diagnostic test ordering behavior? A decision-maker-researcher partnership systematic review. Implement Sci 2011, 6:88.

3. Sahota N, Lloyd R, Ramakrishna A, Mackay J, Prorok J, Weise-Kelly L, Navarro T. Wilczynski N, Haynes RB, the CCDSS Systematic Review Team: Computerized clinical decision support systems for acute care management: a decision-maker-researcher partnership systematic review of effects on process of care and patient outcomes. Implement Sci 2011, 6:91

4. Hemens BJ, Holbrook AM, Tonkin M, Mackay JA, Weise-Kelly L, Navarro T, Wilczynski N, Haynes RB, the CCDSS Systematic Review Team: Computerized clinical decision support systems for drug prescribing and management: a decision-maker-researcher partnership systematic review. Implement Sci 2011, 6:89.

5. Nieuwlaat R, Connolly S, Mackay JA, Weise-Kelly L, Navarro T, Wilczynski NL, Haynes RB, the CCDSS Systematic Review Team: Computerized clinical decision support systems for therapeutic drug monitoring and dosing: a decision-maker-researcher partnership systematic review. Implement Sci 2011, 6:90.

6. Roshanov PS, Misra S, Gerstein HC, Garg AX, Sebaldt RJ, Mackay JA, WeiseKelly L, Navarro T, Wilczynski NL, Haynes RB, the CCDSS Systematic Review Team: Computerized clinical decision support systems for chronic disease management: a decision-maker-researcher partnership systematic review. Implement Sci 2011, 6:92.

7. Holbrook A, Pullenayegum E, Thabane L, Troyan S, Foster G, Keshavjee K, Chan D, Dolovich L, Gerstein H, Demers C, Curnew G: Shared electronic vascular risk decision support in primary care: Computerization of Medical Practices for the Enhancement of Therapeutic Effectiveness (COMPETE III) randomized trial. Arch Intern Med 2011, 171:1736-1744.

8. Holbrook A, Thabane L, Keshavjee K, Dolovich L, Bernstein B, Chan D, Troyan S, Foster G, Gerstein H: Individualized electronic decision support and reminders to improve diabetes care in the community: COMPETE II randomized trial. Can Med Assoc J 2009, 181:37-44.

9. MacLean CD, Gagnon M, Callas P: The Vermont Diabetes Information System: a cluster randomized trial of a population based decision support system. J Gen Intern Med 2009, 24:1303-1310.

10. Christian JG, Bessesen DH, Byers TE, Christian KK, Goldstein MG, Bock BC: Clinicbased support to help overweight patients with type 2 diabetes increase physical activity and lose weight. Arch Intern Med 2008, 168:141-146.

11. Cleveringa FG, Gorter KJ, van den Donk M, Rutten GE: Combined task delegation, computerized decision support, and feedback improve cardiovascular risk for type 2 diabetic patients: a cluster randomized trial in primary care. Diabetes Care 2008, 31:2273-2275.

12. Peterson KA, Radosevich DM, O'Connor PJ, Nyman JA, Prineas RJ, Smith SA, Arneson TJ, Corbett VA, Weinhandl JC, Lange CJ, Hannan PJ: Improving diabetes care in practice: findings from the TRANSLATE trial. Diabetes Care 2008, 31:2238-2243.

13. Augstein P, Vogt L, Kohnert KD, Freyse EJ, Heinke P, Salzsieder E: Outpatient assessment of Karlsburg Diabetes Management System-based decision support. Diabetes Care 2007, 30:1704-1708.

14. Filippi A, Sabatini A, Badioli L, Samani F, Mazzaglia G, Catapano A, Cricelli C: Effects of an automated electronic reminder in changing the antiplatelet drug-prescribing behavior among Italian general practitioners in diabetic patients: an intervention trial. Diabetes Care 2003, 26:1497-1500.

15. Meigs JB, Cagliero E, Dubey A, Murphy-Sheehy P, Gildesgame C, Chueh H, Barry MJ, Singer DE, Nathan DM: A controlled trial of web-based diabetes disease management: the MGH diabetes primary care improvement project. Diabetes Care 2003, 26:750-757

16. Lobach DF, Hammond W: Computerized decision support based on a clinical practice guideline improves compliance with care standards. Am J Med 1997, 102:89-98.

17. Nilasena DS, Lincoln MJ: A computer-generated reminder system improves physician compliance with diabetes preventive care guidelines. Proc Annu Symp Comput Appl Med Care 1995, :640-645.

18. Mazzuca SA, Vinicor F, Einterz RM, Tierney WM, Norton JA, Kalasinski LA: Effects of the clinical environment on physicians' response to postgraduate medical education. Am Educ Res J 1990, 27:473-488. 
19. Thomas RE, Croal BL, Ramsay C, Eccles M, Grimshaw J: Effect of enhanced feedback and brief educational reminder messages on laboratory test requesting in primary care: a cluster randomised trial. Lancet 2006, 367:1990-1996.

20. Derose SF, Dudl JR, Benson VM, Contreras R, Nakahiro RK, Ziel FH: Point of service reminders for prescribing cardiovascular medications. Am J Manag Care 2005, 11:298-304.

21. Sequist TD, Gandhi TK, Karson AS, Fiskio JM, Bugbee D, Sperling M, Cook EF, Orav EJ, Fairchild DG, Bates DW: A randomized trial of electronic clinical reminders to improve quality of care for diabetes and coronary artery disease. J Am Med Inform Assoc 2005, 12:431-437.

22. Thomas JC, Moore A, Qualls PE: The effect on cost of medical care for patients treated with an automated clinical audit system. J Med Syst 1983, 7:307-313.

23. Martin DC, Berger ML, Anstatt DT, Wofford J, Warfel D, Turpin RS, Cannuscio CC, Teutsch SM, Mansheim BJ, Turpin RS: A randomized controlled open trial of population-based disease and case management in a Medicare Plus Choice health maintenance organization. Prev Chronic Dis 2004, 1:A05.

24. Demakis JG, Beauchamp C, Cull WL, Denwood R, Eisen SA, Lofgren R, Nichol K, Woolliscroft J, Henderson WG: Improving residents' compliance with standards of ambulatory care: results from the VA Cooperative Study on Computerized Reminders. JAMA 2000, 284:1411-1416.

25. Hetlevik I, Holmen J, Kruger O: Implementing clinical guidelines in the treatment of hypertension in general practice. Evaluation of patient outcome related to implementation of a computer-based clinical decision support system. Scand J Primary Health Care 1999, 17:35-40.

26. Zeger SL, Liang K-Y, Albert PS: Models for longitudinal data: a generalized estimating equation approach. Biometrics 1988, 44:1049-1060.

27. StataCorp: Stata Statistical Software: Release 11. College Station, TX: StataCorp LP; 2009.

28. Lobach DF: Electronically distributed, computer-generated, individualized feedback enhances the use of a computerized practice guideline. Proc AMIA Annu Fall Symp 1996, :493-497.

29. Fortin M, Bravo G, Hudon C: Prevalence of multimorbidity among adults seen in family practice. Ann Family Med 2005, 3:223-228.

doi:10.1186/1472-6947-12-63

Cite this article as: Roshanov et al:: Impact of a computerized system for evidence-based diabetes care on completeness of records: a beforeafter study. BMC Medical Informatics and Decision Making 2012 12:63.

\section{Submit your next manuscript to BioMed Central and take full advantage of:}

- Convenient online submission

- Thorough peer review

- No space constraints or color figure charges

- Immediate publication on acceptance

- Inclusion in PubMed, CAS, Scopus and Google Scholar

- Research which is freely available for redistribution 